\title{
Dikkat Eksikliği/Hiperaktivite Bozukluğu Tanılı Çocuk ve Ergenlerde Yeme ve Uyku Alışkanlıklarının Değerlendirilmesi
}

\section{Evaluation of Eating Attitudes and Sleep Patterns in Children and Adolescents with Attention Deficit/Hyperactivity Disorder}

\author{
Öznur Bilaç ${ }^{1 *}$ Tuğçe Canol$^{1}$, Canem Kavurma², Yetiş Işıldar², Şermin Yalın Sapmaz ${ }^{1}$, Birsen Şentürk Pilan ${ }^{3}$, Ebru \\ Çatuk $^{2}$, Gülçin Uzunoğlu², İlknur Sevinç²
${ }^{1}$ Manisa Celal Bayar Üniversitesi, Tıp Fakültesi, Çocuk ve Ergen Ruh Sağlığı ve Hastalıkları Anabilim Dalı, Manisa, Türkiye
${ }^{2}$ Manisa Ruh Salığı ve Hastalıkları Hastanesi, Çocuk ve Ergen Psikiyatri Kliniği, Manisa, Türkiye
${ }^{3}$ Ege Üniversitesi, Tıp Fakültesi, Çocuk ve Ergen Ruh Sağlığı ve Hastalıkları Anabilim Dalı, Manisa, Türkiye

e-mail: oznurbilac@gmail.com, tugcecanol@hotmail.com, canemkavurma@gmail.com, yetisisildar@outlook.com, drserminyalin@hotmail.com,drbirsensenturk@yahoo.com, ebruy86@gmail.com,gulcin.boluk_09@hotmail.com, ilknursevinc@hotmail.com

ORCID: 0000-0001-8369-6215

ORCID: 0000-0002-5314-3086

ORCID: 0000-0002-1644-4859

ORCID: 0000-0002-4885-2478

ORCID: 0000-0002-1084-5053

ORCID: 0000-0002-4580-7655

ORCID: 0000-0002-8313-7744

ORCID: 0000-0001-5948-5223

ORCID: 0000-0001-7833-0243

*Sorumlu yazar/ Corresponding Author: Öznur Bilaç

Gönderim Tarihi / Received: 09.11.2020

Kabul Tarihi / Accepted: 09.12.2020

DOI: $10.34087 /$ cbusbed. 823404

\section{Öz}

Giriş ve Amaç: Bu çalışmanın amacı Dikkat Eksikliği/Hiperaktivite Bozukluğu (DEHB) tanılı 11-17 yaş arası çocuk ve ergenlerin yeme tutumları ve uyku paternlerinin sağlıklı kontrollerle karşılaştırılarak incelenmesidir.

Gereç ve Yöntemler: 11-17 yaş arası 35 DEHB tanılı çocuk ve ergen ile yaş ve cinsiyet olarak eşleştirilmiş herhangi bir psikopatolojisi olmayan 11-17 yaş arası 35 sağlıklı kontrol örneklemi oluşturdu. Her iki gruba sosyodemografik veri formu, Okul Çağı Çocukları için Duygulanım Bozuklukları ve Şizofreni Formu-Şimdi ve Yaşam boyu şekli Türkçe Uyarlaması (K-SADS-PL), Yeme Tutumu Testi (YTT), Düzey-2 Uyku Bozukluğu-6-17 Yaş Arası Çocuğun Ebeveyn Formu, Düzey-2 Uyku Bozukluğu-11-17 Yaş Arası Çocuk formu uygulandı.

Bulgular: DEHB tanılı grup ve kontrol grubu arasında Düzey-2 Uyku Ölçeği Ebeveyn Formu ve YTT toplam puanlarında istatistiksel olarak anlamlı fark saptand $1(p<0,001)$. Ebeveynleri tarafından uyku sorunu yaşadığı belirtilen çocukların yeme tutumları açısından da korele olacak şekilde sorun yaşadığı saptandı $(\mathrm{p}=0,018)$. Benlik saygısı çok sorunlu olan çocuklarda uyku ölçeği ebeveyn formu puanlarının istatistiksel olarak anlamlı olarak farklılaştığı saptandı $(\mathrm{p}=0,019)$.

Sonuç: Çalışmamızın sonuçları uyku ve yeme sorunlarının DEHB tanılı çocuk ve ergenlerde sanıldığından yaygın olabileceğini, klinik değerlendirmelerde ayrıca göz önünde bulundurulması gerektiğini düșündürmektedir.

Anahtar kelimeler: Çocuk ve ergen, DEHB, Yeme, Uyku.

\section{Abstract}

Objective: The aim of the study is to compare the eating attitudes and sleep patterns of children and adolescents aged 11-17 with Attention Deficit/Hyperactivity Disorder (ADHD) compared with healty controls. 
Material and Methods The sample was consisted of 35 children and adolescents with ADHD and 35 healty controls that matched in terms of age and gender between the ages of 11-17. Sociodemographic Form, the Schedule for Affective Disorders and Schizophrenia for School-Age Children-Present and Lifetime version-Turkish (K-SADS-PLTR) interview, Eating Attitude Test (EAT), Child and Parent Forms of DSM-5 Level 2 Sleep Disorders were applied to in both groups.

Results: A statistically significant difference was found between the ADHD group and the controls in the Level-2 Sleep Scale Parent Form and EAT total scores $(\mathrm{p}<0.001)$. It was found that children who were reported to have sleep problems by their parents also had problems in eating attitudes $(\mathrm{p}=0.018)$. The sleep scale parent form scores differed significantly in children with very problematic self esteem $(\mathrm{p}=0.019)$.

Conclusion: The results of our study suggest that sleep and eating problems may be common in children and adolescents with ADHD, and should be considered in clinical evaluations.

Keywords: ADHD, Child and adolescent, Eating, Seep.

\section{Giriş}

Dikkat eksikliği hiperaktivite bozukluğu (DEHB), işlevsel bozulmaya neden olan dikkat eksikliği, aşırı hareketlilik ve dürtüsellikle karakterize, yüksek oranda eş bozukluk gösteren, kronik nörogelişimsel bir bozukluktur [1]. DEHB'nin diğer psikiyatrik bozukluklarla yüksek birliktelik gösterdiği sıkça bildirilmiştir. Bunlara ek olarak, çeşitli tıbbi-medikal sorunlar (silik fiziksel anormallikler, alerjik ve nörolojik hastalıklar, obezite ve yeme bozuklukları, travmatik yaralanmalar, riskli cinsel davranıșlar, uyku bozuklukları vb.), mesleki, adli ve akademik sorunlar ve bütün bunların sonucu olarak da artmıș tedavi harcamalarının da bu hastalarda yüksek oranlarda görüldüğü belirlenmiştir [2].

DEHB, çocuk ve ergenlerde en sık görülen psikiyatrik bozukluklardan birisi olup bir meta-analiz çalışmasında tüm dünyada sıklığının \%5,29 olduğu bildirilmiştir [3]. DEHB günümüzde sadece bireysel bir problem olarak görülmemektedir. Ülkelerin sağlık ve okul politikalarını etkileyen bir durum olarak karşımıza çıkan bu bozukluk, çocuğun okuldaki başarısına, sosyal yaşantısına ve gelecekteki eğitim sürecine önemli zararlar verebilmektedir [4]. DEHB ile yeme bozukluklarının ilişkisi ise, bașta obezite olmak üzere son zamanlarda giderek daha çok ilgi çekmeye bașlamıștır. Bu ilișki, DEHB'nin yeme davranıșlarını etkileyerek obeziteye yol açabilmesi, tıkınırcasına yeme davranıșlarına dürtüselliğin katkısı ve hipokretin/oreksin veya dopaminerjik sistem anormallikleri ile açıklanmaya çalıșılmıștır.

DEHB tanısı almıș bireyler bu tanıyı almamıș olanlara göre daha çok uyku sorunu yaşarlar. Uykuya dalma güçlüğü DEHB tanılı çocukların \%56'sında görülebilir. DEHB'li olguların \%39'unda uyku sürekliliğinde azalma gözlendiği bildirilmiștir [2]. DEHB'li çocuklarda orta şiddette veya şiddetli uyku sorunlarının bakım verenlerin ruh sağlığı, iş durumları ve ailenin işlevselliği ile yakından ilişkili olduğu gösterilmiştir. Corkum ve arkadaşları tarafından yapılan bir gözden geçirme çalışmasında, DEHB'li çocukların ailelerinin \%25-55 sıklıkla uyku sorunlarından yakındıkları gösterilmiştir [5].

Araştırmalara göre, çocukluk çağında tanı konan bireylerin \%30-70'i ergenlik ve erişkinlik döneminde de belirgin zorluklar göstermeye devam etmektedir [6]. DEHB'nin yaşam boyu yol açabileceği riskler arasında akademik başarısızlık ve ilişki sorunlarının yanında sigara ve alkol-madde kullanım bozuklukları, yasal sorunlar, kaza ve yaralanmalar, mesleki alanda başarısızlık ve sağlıksız yaşam biçimi, uyku ve yeme bozuklukları yer alır [5]. Bu nedenlerle DEHB'si olan çocuk ve ergenlerde yeme ve uyku alışkanlıklarının da değerlendirilmesi önemlidir. Yapılmış çalışmalarda DEHB'li çocuk ve ergenlerde yeme ve uyku alışkanlıklarını birlikte aynı örneklemde değerlendiren bir araştırmaya rastlanmamıştır. Bu özden hareketle çalışmada dikkat eksikliği ve hiperaktivite bozukluğu olan çocuk ve ergenlerde yeme ve uyku alışkanlıklarının değerlendirilmesi amaçlanmıştır. DEHB'si olan çocuk ve ergenlerde yeme ve uyku alışkanlıkları değerlendirilmesi, alanda yapılacak çalışmalara 1 şık tutacak ve klinik değerlendirmelerde sadece DEHB semptomlarına değil, bu çocuk ve gençlerin uyku ve yeme alışkanlıklarının da değerlendirilmesi konusunda farkındalığı arttıracaktır.

\section{Materyal ve Metot}

Eylül 2018- Haziran 2019 tarihleri arasında 11-17 yaş arası, kendisi ve vasisi tarafından araştırmaya katılmayı kabul eden 70 çocuk ve ergen araştırmanın evrenini oluşturdu. Bu evreni, DEHB tanılı ve tedavi almamış 35 olgu, kontrol grubu olarak daha önce çocuk psikiyatrisi polikliniği başvurusu ve yapılan klinik değerlendirmede aktif psikopatolojisi olmayan, yaş ve cinsiyet açısından örneklem grubuna eşleştirilmiş 35 sağlıklı çocuk ve ergen oluşturdu.

Çalışmaya Manisa Celal Bayar Üniversitesi Etik Kurulu'ndan (09.05.2018 tarihli, 20.47A.4A6 onay kodlu) etik kurul onayı alındıktan sonra başlandı. Çocuk ve ergenlerin tanıları Amerikan Psikiyatri Birliği Mental Bozuklukların Tanısal ve Sayımsal El Kitabı, Beşinci Baskısı (DSM-5)'na dayalı Okul Çağı Çocukları için Duygulanım Bozuklukları ve Şizofreni Formu-Şimdi ve Yaşam boyu Şekli Türkçe Uyarlaması (K-SADS-PL) (ÇDŞG-ŞY-DSM-5-T) ile yapılan klinik görüşme ile belirlendi. Her iki gruba sosyodemografik Veri Formu, Yeme Tutumu Testi, Düzey-2 Uyku Bozukluğu-6-17 Yaş Arası Çocuğun Ebeveyni/Vasisi, Düzey-2 Uyku Bozukluğu-11-17 Yaş Arası Çocuk Formu uygulandı.

\subsection{Değerlendirme Araçlarl}

2.1.1. Sosyodemografik veri formu: Çalışmada yer alan ergenlerin sosyodemografik özelliklerini saptamak 
amacıyla yazarlar tarafından oluşturulmuştur. Soruların bazıları Likert tipi, bazıları "Evet/Hayır" şeklinde, bazıları da açık uçlu şekilde sorulmuştur.

2.1.2. Okul Çağı Çocuklart için Duygulanım Bozukluklarl ve Şizofreni Formu-Şimdi ve Yaşam boyu Şekli DSM-5 Kasım 2016 -Türkçe Uyarlaması (ÇDŞGŞY-DSM-5-T): Kaufman ve arkadaşlarının (2016) DSM5 tanı ölçütlerine göre güncelledikleri, yarı yapılandırılmış bu görüşme çizelgesinin Türkçe uyarlaması araştırmacılar tarafından yapılmış, çeviri ve geri-çeviri metinlerindeki farklılıklar ve görüşme çizelgesinin işlerliğinin değerlendirildiği anne-baba ve çocuklarla yapılan deneme görüşmelerinin gözden geçirilmesi ile ÇDŞG-ŞYDSM-5-T son şeklini almıştır [7]. Geçerlilik ve güvenilirliği 2018 yılında Ünal ve arkadaşları tarafından yapılmıştır [8].

2.1.3. Yeme Tutum Testi (YTT): Hem yeme bozukluğu olan hastalardaki, hem de yeme bozukluğu olmayan bireylerdeki yeme davranışındaki olası bozuklukları değerlendirmek amacıyla geliştirilmiş bir öz bildirim ölçeğidir. YTT'nin yeme davranışı bozuklukları için iyi bir tarama aracı olduğu düşünülmektedir. Garner ve Garfinkel (1979) tarafindan geliştirilmiștir [9]. Toplam puanın düzeyi psikopatolojinin düzeyi ile doğrudan ilişkilidir. Türkçe geçerlilik ve güvenilirlik çalışması Savaşır ve Erol (1989) tarafindan yapılmıştır (10).

2.1.4. DSM-5 Düzey 2 Uyku Bozukluğu Ölçeği - Çocuk ve Ergen ve Ebeveyn Formu: Toplam sekiz maddeden oluşmaktadır. 6-17 yaş çocuk ve ergenlerin anne babaları tarafından doldurulan ebeveyn formu ve 11-17 yaş arası ergenlerin kendilerinin doldurduğu bir öz bildirim formu bulunmaktadır. Her bir madde için, çocuktan geçtiğimiz yedi gün içerisinde uyku bozukluğu ile ilişkili mevcut olan belirtilerinin şiddetini puanlaması istenmektedir.
Toplam puan 8-40 arasında değiş̧mektedir ve yüksek skorlar uyku bozukluğu ile ilişkili belirtilerin daha şiddetli olduğunu göstermektedir [11]. Türkçe geçerlilik ve güvenilirliği, Özek Erkuran ve ark. tarafından yapılmıştır [12].

2.1.5. Iş̧levsellik değerlendirmesi: DEHB tanısı olan grubun ebeveyninden kardeş ilişkileri, arkadaş ilişkileri, okul ödevlerini yapma ve genel olarak çocuğun evdeki uyumu sorgulandı. Öğretmenden, olgunun genel olarak sorunlu olup olmadiğ 1 , okulda arkadaş ilişkileri, genel ders başarısı, benlik saygısı sorgulandı. Bütün alanlar 'hiç sorun yok', 'biraz sorunlu' ve 'çok sorunlu' olarak sınıflanmış olup benzer yaklaşımlar daha önce yapılmış olan epidemiyolojik çalışmalarda kullanılmıştır $[13,14]$.

2.2. Istatistiksel Analiz

İstatistiksel analiz için SPSS 20.0 programı kullanıldı. Kategorik değişkenler sıklık (s) ve yüzde (\%) cinsinden ifade edildi. Verilerin değerlendirmesinde tanımlayıcı istatistikler (ortalama, standart sapma, minimum, maksimum, yüzde) ve değişkenlerin karşılaştırılmasında kategorik veriler için ki kare, olgu ve kontrol grubu arasındaki ölçek puan karşılaştırılması T-test analizi kullanılarak değerlendirildi. Ölçek puanları arası korelasyon değerlendirmesinde Pearson korelasyon analizi, DEHB grubunda işlevsellik ile ölçek puanları arasındaki ilişkinin değerlendirilmesinde Kruskal-Wallis analizi kullanıldı. $\mathrm{p}<0,05$ değeri istatistiksel anlamlılık düzeyi olarak kabul edildi.

\section{Bulgular ve Tartışma}

3.1 Bulgular

Çalışmamıza olgu grubu 35 (\%50), kontrol grubu 35 $(\% 50)$ olmak üzere toplam 70 çocuk katıldı. Olgu ve kontrol grubunun sosyodemografik veriler açısından karşılaştırılması Tablo 1'de verildi.

Tablo 1. Sosyodemografik veriler açısından grupların karşılaştırılması

\begin{tabular}{|c|c|c|c|}
\hline & Olgu & Kontrol & $\mathbf{p}$ \\
\hline & $O r t \pm S S$ & $O r t \pm S S$ & \\
\hline \multirow[t]{2}{*}{ Yaş } & $13,82 \pm 1,57$ & $13,94 \pm 1,41$ & 0,995 \\
\hline & Sayı (\%) & Sayı (\%) & \\
\hline \multicolumn{4}{|l|}{ Cinsiyet } \\
\hline $\mathrm{K} 1 \mathrm{z}$ & $7(20)$ & $7(20)$ & \multirow[t]{2}{*}{1,00} \\
\hline Erkek & $28(80)$ & $28(80)$ & \\
\hline \multicolumn{4}{|l|}{ Aile bütünlüğü } \\
\hline Anne baba birlikte & $31(88,6)$ & $28(80)$ & \multirow[t]{2}{*}{, 513} \\
\hline Anne baba ayrılmış & $4(11,4)$ & $7(20)$ & \\
\hline \multicolumn{4}{|l|}{ Anne eğitim durumu } \\
\hline Okur yazar-ilkokul & $16(45,7)$ & $12(34,3)$ & \multirow{3}{*}{,434 } \\
\hline Ortaokul & $5(14,3)$ & $7(20)$ & \\
\hline Lise-üniversite & $14(40)$ & $16(45,7)$ & \\
\hline \multicolumn{4}{|l|}{ Baba eğitim durumu } \\
\hline Okur yazar-ilkokul & $16(45,7)$ & $9(25,7)$ & \multirow{3}{*}{, 149} \\
\hline Ortaokul & $4(11,4)$ & $8(22,9)$ & \\
\hline Lise-üniversite & $14(40)$ & $18(51,4)$ & \\
\hline
\end{tabular}


Çalışmamıza katılan çocuklar yaşları açısından karşılaştırıldı, olgu ve kontrol grubu arasında anlamlı bir fark bulunmadı. Çalışmamıza katılan 70 çocuğun \%20'si k1z $\quad(n=14), \quad \% 80$ 'i erkektir $\quad(n=56)$. Gruplar karşılaştırıldığında cinsiyetleri açısından anlamlı bir fark saptanmadı. Aile bütünlüğü değerlendirildiğinde olgu ve kontrol grubu arasında anlamlı bir farklılık saptanmadı. Anne ve babanın eğitim düzeyi açısından olgu ve kontrol grubunda istatistiksel olarak anlamlı bir fark bulunmadı.
Düzey-2 Uyku Ölçeği Ebeveyn Formu, Düzey-2 Uyku Ölçeği Çocuk Formu ve Yeme Tutum Testi toplam puanlarının gruplara göre karşılaştırılması Tablo 2'dedir. Olgu ve kontrol grubu arasında Düzey-2 Uyku Ölçeği Ebeveyn Formu toplam puanlarında istatistiksel olarak anlamlı fark saptanırken, Çocuk Formu toplam puanlarında anlamlı fark saptanmadı. Yeme Tutum Testi toplam puanları karşılaştırıldığında iki grup arası fark istatistiksel olarak anlamlı bulundu.

Tablo 2. Düzey-2 Uyku Ölçeği Ebeveyn Formu, Düzey-2 Uyku Ölçeği Çocuk Formu ve Yeme Tutum Testi toplam puanlarının gruplara göre karşılaştırılması

\begin{tabular}{|c|c|c|c|c|}
\hline 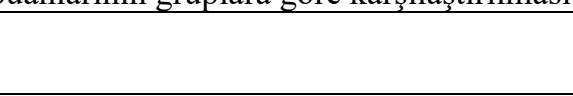 & $\begin{array}{c}\text { Olgu } \\
\text { Ort } \pm \text { SS }\end{array}$ & $\begin{array}{c}\text { Kontrol } \\
\text { Ort } \pm \text { SS }\end{array}$ & $\mathbf{t}$ & $\mathbf{p}$ \\
\hline Düzey-2 Uyku Ölçeği Ebeveyn Formu & $18,00 \pm 7,29$ & $12,57 \pm 3,97$ & 3,86 & ,000 \\
\hline Düzey-2 Uyku Ölçeği Çocuk Formu & $16,62 \pm 7,77$ & $14,17 \pm 4,94$ & 1,57 & ,119 \\
\hline Yeme Tutum Testi & $22,40 \pm 8,87$ & $11,28 \pm 4,01$ & 6,75 & ,000 \\
\hline
\end{tabular}

Ort: Ortalama, SS: Standart sapma, p : p değeri

Çalışmada uygulanan ölçeklerin korelasyon analizleri Tablo 3'tedir. Çalışmamızda, ölçeklerde ebeveynleri tarafından uyku sorunu yaşadığı belirtilen çocukların yeme tutumları açısından da korele olacak șekilde sorun yaşadığı saptandı.

Tablo 3. Pearson korelasyon değerleri

\begin{tabular}{|l|c|c|c|c|}
\hline & Yaş & $\begin{array}{c}\text { Düzey-2 Uyku Ölçeği } \\
\text { Ebeveyn }\end{array}$ & $\begin{array}{c}\text { Düzey-2 Uyku Ölçeği } \\
\text { Çocuk }\end{array}$ & Yeme Tutum Testi \\
\hline Yaş & 1,000 &, 112 &, 189 &, 161 \\
\hline $\begin{array}{l}\text { Düzey-2 Uyku Ölçeği } \\
\text { Ebeveyn toplam puan }\end{array}$ &, 112 & 1,000 & $\mathbf{, 6 2 9}(* *)$ &, $283(*)$ \\
\hline $\begin{array}{l}\text { Düzey-2 Uyku Ölçeği } \\
\text { Çocuk toplam puan }\end{array}$ &, 189 & $\mathbf{, 6 2 9}(* *)$ & 1,000 &, 166 \\
\hline $\begin{array}{l}\text { Yeme Tutum Testi } \\
\text { toplam puan }\end{array}$ &, 161 & $\mathbf{2 8 3}(*)$ &, 166 & 1,000 \\
\hline
\end{tabular}

$* * \mathrm{p}<0,01 * \mathrm{p}<0,05$

Tablo 4'te Kruskal-Wallis test sonuçları verildi. Yapılan analizde öğretmen işlevsellik değerlendirmesine göre benlik saygısı çok sorunlu olan çocuklarda uyku ölçeği ebeveyn formu puanlarının istatistiksel olarak anlamlı olarak farklılaştığ saptand1.

\subsection{Tartışma}

Araştırmamızda elde edilen bulgular, DEHB tanısı olan çocuk ve ergenlerin sağlıklı gruba göre uyku ve yeme davranışlarının sorunlu olduğunu, uyku sorunu ile yeme davranışlarının birbirini etkilediğini düşündürmektedir. Ayrıca DEHB tanısı olan çocuk ve ergenlerin uyku sorunu olmasının, okulda benlik saygısını olumsuz etkilediği görülmüştür. Çalışmamı, bilebildiğimiz kadarıyla DEHB tanılı çocuk ve ergenlerde uyku ve yeme alanlarını aynı örneklemde araştıran ve birbirleri ile olan ilişkisini inceleyen ilk araştırmadır. 
Tablo 4. Düzey-2 Uyku Ölçeği Ebeveyn Formu, Düzey-2 Uyku Ölçeği Çocuk Formu ve Yeme Tutum Testi toplam puanlarının ebeveyn ve öğretmen işlevsellik değerlendirmelerine göre farklılaşıp farklılaşmadığını belirlemek üzere yapılan Kruskal-Wallis Test sonuçları

\begin{tabular}{|c|c|c|c|c|c|c|c|}
\hline & & \multicolumn{2}{|c|}{$\begin{array}{l}\text { Düzey-2 Uyku Ölçeği } \\
\text { Ebeveyn }\end{array}$} & \multicolumn{2}{|c|}{$\begin{array}{c}\text { Düzey-2 Uyku Ölçeği } \\
\text { Çocuk }\end{array}$} & \multicolumn{2}{|c|}{ Yeme Tutumu Testi } \\
\hline & & Ortalama & $\mathrm{p}$ & Ortalama & $\mathrm{p}$ & Ortalama & $\mathrm{p}$ \\
\hline \multirow[t]{16}{*}{ Ebeveyn } & $\begin{array}{l}\text { Arkadaş } \\
\text { ilişkileri }\end{array}$ & & & & & & \\
\hline & Sorun yok & 16,50 & \multirow{3}{*}{,099 } & 17,13 & \multirow{3}{*}{,442 } & 16,88 & \multirow{3}{*}{,466 } \\
\hline & Biraz sorunlu & 16,46 & & 17,07 & & 17,43 & \\
\hline & Çok sorunlu & 27,10 & & 23,40 & & 23,20 & \\
\hline & Kardeş ilişkileri & & & & & & \\
\hline & Sorun yok & 14,40 & \multirow{3}{*}{,139 } & 13,40 & \multirow{3}{*}{, 124} & 17,85 & \multirow{3}{*}{,986 } \\
\hline & Biraz sorunlu & 21,33 & & 21,31 & & 17,86 & \\
\hline & Çok sorunlu & 14,57 & & 16,07 & & 18,57 & \\
\hline & Ödev yapma & & & & & & \\
\hline & Sorun yok & 25,50 & \multirow{3}{*}{, 082} & 20,08 & \multirow{3}{*}{482} & 15,75 & \multirow{3}{*}{,796 } \\
\hline & Biraz sorunlu & 18,25 & & 19,41 & & 17,91 & \\
\hline & Çok sorunlu & 14,23 & & 15,31 & & 19,15 & \\
\hline & Genel uyum & & & & & & \\
\hline & Sorun yok & 19,55 & \multirow{3}{*}{, 827} & 13,55 & \multirow{3}{*}{, 101} & 13,80 & \multirow{3}{*}{,276 } \\
\hline & Biraz sorunlu & 17,75 & & 21,91 & & 18,97 & \\
\hline & Çok sorunlu & 16,72 & & 16,00 & & 20,94 & \\
\hline \multirow[t]{16}{*}{ Öğretmen } & $\begin{array}{l}\text { Arkadaş } \\
\text { ilişkileri }\end{array}$ & & & & & & \\
\hline & Sorun yok & 16,73 & \multirow{3}{*}{,809 } & 14,77 & \multirow{3}{*}{, 354} & 15,00 & \multirow{3}{*}{, 142} \\
\hline & Biraz sorunlu & 18,27 & & 20,00 & & 17,60 & \\
\hline & Çok sorunlu & 19,79 & & 19,71 & & 24,43 & \\
\hline & Ders başarısı & & & & & & \\
\hline & Sorun yok & 18,38 & \multirow{3}{*}{,759 } & 17,56 & \multirow{3}{*}{, 860} & 20,25 & \multirow{3}{*}{,379 } \\
\hline & Biraz sorunlu & 17,12 & & 17,57 & & 16,07 & \\
\hline & Çok sorunlu & 20,58 & & 20,08 & & 21,75 & \\
\hline & Benlik saygısı & & & & & & \\
\hline & Sorun yok & 14,87 & \multirow{3}{*}{,019 } & 15,05 & \multirow{3}{*}{,059 } & 16,37 & \multirow{3}{*}{,441 } \\
\hline & Biraz sorunlu & 17,22 & & 18,17 & & 18,22 & \\
\hline & Çok sorunlu & $27,50 *$ & & 25,79 & & 22,14 & \\
\hline & $\begin{array}{l}\text { Okul genel } \\
\text { uyumu }\end{array}$ & & & & & & \\
\hline & Sorun yok & 15,42 & \multirow{3}{*}{, 144} & 15,92 & \multirow{3}{*}{, 243} & 18,83 & \\
\hline & Biraz sorunlu & 17,03 & & 17,06 & & 15,38 & ,282 \\
\hline & Çok sorunlu & 24,64 & & 23,71 & & 22,57 & \\
\hline
\end{tabular}

*: post hoc test sonuçlarına göre farkı oluşturan grup 
Yazında DEHB tanılı çocuk ve ergenlerin \%53-64'ünün uyku sorunları olduğu, çoğunlukla uykuya dalma güçlüğü ve uyku sürekliliğinde azalma ve bu yakınmaların ilaç kullanımı ile ilișki göstermediği bildirilmektedir [2]. Ülkemizde 83 DEHB tanılı ve tedavi almamış çocuk ve ergenle yapılmış bir çalışmada, sağlıklı kontrollere göre DEHB tanısı alan grubun anlamlı düzeyde uyku sorunu yaşadıkları ve bunun işlevselliği etkilediği saptanmıştır [15]. Owens ve arkadaşları, 46 DEHB tanılı ve tedavi almamış okul çağı çocuğu ile yaptıkları bir çalışmada, sağlıklı kontrollere göre hem kendilerinin, hem de ebeveynlerinin uyku sorununu anlamlı düzeyde bildirdiklerini saptamışlardır [16]. Yazını destekler şekilde çalışmamızda ebeveynler uyku sorunu bildirmişlerdir. Ancak farklı olarak bizim örneklemimizde, ergenler uyku sorunu bildirmemişlerdir. $\mathrm{Bu}$, ergenlerin uyku ihtiyacını daha az hissetmeleri ile ilgili olabilir ve sorun olarak algılamamış olabilirler. Eyüboğlu ve Eyüboğlu'nun araştırmalarında [15] elde ettikleri sonuçlardan farklı olarak, öğretmenin bildirdiği işlevsellik değerlendirmesinde benlik saygısında uyku sorunu ile ilișki saptanması dışında diğer alanlardaki işlevsellik etkilenmesi ile uyku arasında bir ilişki saptanmamıştır.

Bugüne kadar çocuk ve ergenlerde yeme tutumları ve DEHB arasındaki ilişkinin sınırlı sayıda çalışma ile araştırıldığı dikkat çekmektedir [17]. Yapılmış sınırlı sayıdaki çalışmalarda ise DEHB ile anormal yeme tutumu arasında bir ilişki olduğu ve DEHB'nin anormal yeme tutumunu arttırdığını bildirmişlerdir $[17,18]$. Çin'de ortalama yaşları 10,6 olan 785 çocukla yapılmış kesitsel bir çalışmada, DEHB semptomlarının aşırı yeme ve az yeme gibi emosyonel yeme davranışları ile ilişkili olduğu bulunmuştur [17]. Çalışmamızda, DEHB semptomları ve yeme tutumları alt kategorilere ayrilarak incelenmemiş olsa da; DEHB tanılı grupta yeme tutum puanlarının sağlıklı gruba göre daha yüksek olduğu ve bu sonucun yazını desteklediği görülmüştür.

Yeme ve uyku, kişinin fiziksel ve psikolojik işlevselliğini etkileyen iki önemli biyolojik süreçtir. T1kanırcasına yeme davranışının uyku sorunları ile ilişkili olduğu saptanmıș ve uyku sorunlarının düzensiz bir yeme davranışı olan tıkanırcasına yeme davranışı ve dolayısı ile obezite ile ilişkili olduğu bildirilmiştir. Uyku ve yeme davranışı arasındaki ilişki gelişimsel bir dönem olan ergenlik döneminde henüz yeterince araştırılmamıştır [19]. 7-11 yaş arası çocuklarla yapılmış bir çalışmada obezitesi ve tıkanırca yeme sorunu olan çocuklarda daha fazla uyku sorunu olduğu görülmüştür [20]. Obezite ile dürtüsellik arasında bir ilişki olduğu, obezite tedavis gören çocukların büyük bir kısmında (\%58) DEHB tanısının varlığı ve DEHB olan çocukların vücut-kitle indekslerinin kontrol grubuna göre daha yüksek olduğu gösterilmiştir [21,22]. Ülkemizde yakın zamanlı 12-18 yaş arası 106 ergen ile yapılmış bir çalışmada, aşırı kiloluluk/ obezite tan1lı grupta en s1k tespit edilen psikiyatrik bozukluğun \%39,6 oranında DEHB olduğu saptanmıştır [23]. DEHB tanılı çocukların uykularında bozulma olduğu, DEHB semptomlarının uykuyu bozarak enerji eksikliğini telafi etmek amacıyla yeme davranışını etkiliyor olabileceği öne sürülmektedir [24,25]. Çalışmamızda DEHB tanısı olan çocuk ve ergenlerin uyku ve yeme sorunları arasında bir ilişki olduğu görülmüştür. Yazında bu ilişkiyi DEHB tanılı çocuk ve ergenlerde değerlendiren bir araştırmaya rastlanılmamış olup daha geniş örneklemli, tedavi alan ve almayan grupların da karşılaştırıldığ 1 uzun izlem çalışmalarının gerekli olduğu anlaşılmaktadır.

Araştırmamız DEHB'de uyku ve yeme davranışının bilebildiğimiz kadarıyla aynı örneklemde incelendiği ilk araştırma olup, çalışmaya alınan olgularda ilaç kullanımı ve ek psikiyatrik hastalık olmaması gibi güçlü yanlarına karşın araştırmanın bazı sınırlılıkları vardır. Kesitsel nitelikte, örneklem sayısının az, DEHB'nin ve yeme tutumlarının alt tip ayrımının yapılmamış olması önemli sinırlılıklardır.

\section{Sonuç}

Çalışmamızın sonuçları, uyku ve yeme sorunlarının DEHB tanılı çocuk ve ergenlerde sanıldığından yaygın olabileceğini, klinik değerlendirmelerde ayrıca göz önünde bulundurulması gerektiğini düșündürmektedir..

\section{Referanslar}

1. Yorbık, Ö, Mutlu, C, Ergenlerde Dikkat Eksikliği Hiperaktivite Bozukluğu, Turkiye Klinikleri Journal, Child Psychiatry-Special Topics, 2015, 1(1), 35-38.

2.Tufan, A.E, Yaluğ, İ, Dikkat Eksikliği Hiperaktivite Bozukluğunda Tıbbi Eş Tanılar, Psikiyatride Güncel Yaklașımlar-Current Approaches In Psychiatry, 2009, 1, 187-200

3. Hergüner, S, Hergüner, A, Dikkat Eksikliği Hiperaktivite Bozukluğu olan Çocuk ve Ergenlerde Eşlik Eden Psikiyatrik Bozukluklar, Nöropsikiyatri Arșivi, 2012, 49, 114-118.

4.Kaymak Özmen, S, Dikkat Eksikliği Hiperaktivite Bozukluğu'nda Çok Yönlü Eğitim Uygulamalarının Etkisi, Eğitim ve Bilim, 2011, 36, 161-164.

5.Yürümez, E, Dikkat Eksikliği Hiperaktivite Bozukluğu Olan Cocuklarda Uykunun Yaşam Kalitesi ile İlişkisinin İncelenmesi, Yayınlanmamış Uzmanlık Tezi, 2011

6. Duran, Ş, Fıstıkcı, N, Keyvan, A, Bilici, M, Çalışkan, M, Ayaktan Psikiyatri Hastalarında Dikkat Eksikliği ve Hiperaktivite Bozukluğu: Yaygınlık ve Eştanılar, Türk Psikiyatri Dergisi, 2014, 25(2), 84-93.

7. Kaufman, J, Birmaher, B ve ark, (2016) Schedule for Affective Disorders and Schizophrenia for School-Aged Children: Present and Lifetime Version (K-SADS-PL) DSM-5 November 2016 Working draft. New Haven, Yale University, Child and Adolescent Research and Education.

8. Ünal, F, Öktem, F ve ark, Okul çağı çocukları için duygulanım bozuklukları ve şizofreni görüşme çizelgesi-şimdi ve yaşam boyu şekli-DSM-5 Kasım 2016-Türkçe uyarlamasının (ÇDŞG-ŞYDSM-5-T) geçerlik ve güvenirliği, Türk Psikiyatri Dergisi, 2019, 30, 42-50.

9. Garner, D.M, Garfinkel, P.E, The Eating Attitudes Test: an index of the symptoms os anorexia nervosa, Psychological Medicine, 1979, 9, 273-279.

10. Köroğlu, E, Aydemir, Ö, Psikiyatride Kullanılan Klinik Ölçekler; Ankara: Hekimler Yayın Birliği, 2000

11. American Psychiatric Association (2013) Diagnostic and Statistical Manual of Mental Disorders, Fifth Edition (DSM-5) (Trans. Ed.: E Köroğlu); Ankara: Hekimler Publishing Union, 2013.

12. Özek Erkuran, H, Yalın Sapmaz, S, Herdem, A, Öztürk, M, Bilaç, Ö, Önen, Ö, Uzel Tanrıverdi, B, Köroğlu, E, Aydemir, Ö, DSM-5 Level 2 Sleep Disorders Scale Validity and Reliability of Turkish Form (Form for Children Aged 11-17 Years and Parent Form for Children Aged 6-17 Years), Archives of Neuropsychiatry, 2018, 55, 1-5.

13. Brotman, M.A. Schmajuk, M ve ark., Prevalence, Clinical Correlates, and Longitudinal Course of Severe Mood Dysregulation in Children, Biological Psychiatry, 2006, 60, 991-997.

14. Cho, S.C, Kim, B.N ve ark., Full syndrome and subthreshold attention-deficit/hyperactivity disorder in a Korean community 
sample: comorbidity and temperament findings, European Child\&Adolescent Psychiatry, 2009, 18, 447-457.

15. Eyuboglu, M, Eyuboglu, D, Behavioural sleep problems in previously untreated children with attention deficit hyperactivity disorder, Psychiatry And Clinical Psychopharmacology, 2018, 28 (1), 19-24.

16. Owens, J.A, Maxim, R ve ark., Parental and selfreport of sleep in children with attention-deficit/hyperactivity disorder, Archives of Pediatrics and Adolescent Medicine, 2000,154(6), 549-555.

17. Tong, L, Shi, H, Li, X, Associations among ADHD, abnormal eating and overweight in a non-clinical sample of Asian children, Scientific Reports-Nature, 2017, 7 (1), 2844.

18. Reinblatt, S.P, Leoutsakos, J.M ve ark., Association between binge eating and attention-deficit/hyperactivity disorder in two pediatric community mental health clinics, International Journal of Eating Disorders, 2015, 48(5), 505-511.

19. Cooperi A.R, Loeb, K.L, McGlinchey, E.L, Sleep and eating disorders: current research and future directions, Current Opinion in Psychology, 2020, 34, 89-94.

20. Tzischinsky, O, Latzer, Y, Sleep-wake cycles in obese children with and without binge-eating episodes. Journal of Paediatrics and Child Health, 2006,42, 688-693.

21. Odent, M, Attention deficit hyperactivity disorder (ADHD) and obesity: Two facets of the same disease? Medical Hypotheses, 2010, 74, 139-141.

22. Agranat Meged, A.N, Deitcher, C ve ark., Childhood obesity and attention deficit hyperactivity disorder: A newly described comorbidity in obese hospitalized children, International Journal of Eating Disorders, 2005, 37, 357-359.

23. Işık, Ü, Bağcı, B, Aktepe, E, Kılıç, F, Pirgon, Ö, Obezite Tanıl Ergenlerde Esslik Eden Psikiyatrik Bozuklukların Araștırılması, Turkish Journal of Child and Adolescent Mental Health, 2020, 27(2), 85-90.

24. Fuemmeler, B.F, Sheng, Y ve ark., Associations between attention deficit hyperactivity disorder symptoms and eating behaviors in early childhood, Pediatric Obesity, 2020, 15, e12631.

25. Lunsford-Avery, J.R, Krystal, A.D, Kollins, S.H, Sleep disturbances in adolescents with ADHD: a systematic review and framework for future research, Clinical Psychology Review, 2016, 50, 159-174.

http://edergi.cbu.edu.tr/ojs/index.php/cbusbed isimli yazarın CBU-SBED başlıklı eseri bu Creative Commons Alıntı-Gayriticari4.0 Uluslararası Lisansı ile lisanslanmıştır.

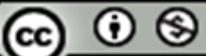

